\title{
Materials Selection for the Canadian Supercritical Water-Cooled Nuclear Reactor Concept
}

\author{
JIAN LI ${ }^{1,2}$ \\ 1.—CanmetMaterials, Hamilton, ON, Canada. 2.-e-mail: jili@nrcan.gc.ca
}

Canada is an active member in the Generation-IV International Forum (GIF). Since 2008, the Canadian Gen-IV team has made significant efforts in materials research to support the development of the Canadian Supercritical Water-cooled Reactor (SCWR) concept.

The Canadian SCWR concept is designed to operate at a core outlet temperature of $625^{\circ} \mathrm{C}$ and $25 \mathrm{MPa}$ of pressure in order to obtain an overall thermal efficiency of $\sim 48 \%$. To achieve this, the peak fuel cladding temperature will be as high as $800^{\circ} \mathrm{C}$. Fuel cladding needs to be thin in order to improve neutron efficiency, which is now expected to be in the range of $0.4-0.6 \mathrm{~mm}$ in thickness. The high temperature and high pressure in the Canadian SCWR concept are so demanding that materials property requirements far exceed those of the materials used in the pressurized water reactor and the boiling water reactor systems. Hence, a large effort on materials $R \& D$ was undertaken in this Canadian national program.

Candidate fuel cladding should meet requirements that include: high temperature mechanical properties, creep resistance, corrosion and stress corrosion cracking (SCC) resistance, including irradiation-assisted stress corrosion cracking (IASCC) and resistance to irradiation damage. Based on these requirements, four candidate alloys, stainless steel 310S, 347H, Alloy-800H, and Inconel-625, were selected for screening assessment in the Canadian SCWR program.

As part of this national program, we established a variety of unique materials production and testing equipment that greatly enhanced the high-temperature materials research capability in Canada. These include but are not limited to:

- High-temperature mechanical testing equip-

Jian $\mathrm{Li}$ is the JOM advisor for the Materials Characterization Committee of the TMS Extraction \& Processing Division, and guest editor for the topic The Canadian Generation IV Supercritical Water-Cooled Nuclear Reactor Conceptual Design in this issue. ment for long-term structural integrity tests

- Supercritical water corrosion and SCC test loops, with oxygen and hydrogen control and monitoring capability, for corrosion and cracking susceptibility tests

- World-class electron microscopy suite for advanced microstructure analyses

- Advanced vacuum melting and casting facility to produce advanced steels and high-temperature alloys

- Super-computer to calculate and simulate irradiation damage

Materials selection for high-temperature components, more specifically the fuel cladding, is identified as one of the most challenging tasks in the development of the Canadian SCWR concept. Within the Canadian SCWR program, extensive materials R\&D work was led by CanmetMATERIALS and CNL with multiple participants from Canadian universities. Support from other GIF partners has also been valuable to the success of this conceptual design.

In February 2015, the Canadian SCWR Conceptual design successfully passed the Canadian Expert Review, and a successful international review was held in October 2015.

The following papers being published under the topic of The Canadian Generation IV Supercritical Water-Cooled Nuclear Reactor Conceptual Design outline some selected highlights of materials R\&D in the Canadian SCWR program. To download any of the papers, follow the url http://link.springer.com/ journal/11837/68/2/page/ 1 to the table of the contents page for the February 2016 issue (vol. 68, no. 2).

- "Overview: Canada's Generation IV International Forum (GIF) Participation and National Program" by Daniel Brady and Cheri-Ann MacKinlay summarizes the international GenIV program and Canada's involvement in the development of the Gen-IV SCWR concept. 
- "Materials Assessment for the Canadian SCWR Core Concept" by Wenyue Zheng, David Guzonas, Kevin P. Boyle, Jian Li, and Su Xu provides an overview of the challenges in the selection of fuel cladding material and the overall results of the Canadian SCWR concept.

- "Machine-able Yttria Stabilized Zirconia Composites for Thermal Insulation in Nuclear Reactors" by J. Lo, R. Zhang, and R. Santos illustrates the development of advanced ceramic insulators for use in the Canadian SCWR.

- "Mechanical Properties of Fuel Cladding Candidate Alloys for Canadian SCWR Concept" by Su $\mathrm{Xu}$ and Babak Shalchi Amirkhiz summarizes the evaluation of high temperature mechanical properties of candidate fuel cladding alloys.

- "Corrosion Assessment of Candidate Materials for Fuel Cladding in Canadian SCWR" by Yimin
Zeng and David Guzonas summarizes the assessment of high-temperature corrosion resistance of fuel cladding alloys.

- "Developing Corrosion Prevention Coating Solution for the Canadian SCWR Concept" by Xiao Huang presents the development of corrosion prevention and thermal insulation coatings.

- "Microstructure Instability of Candidate Fuel Cladding Alloys: Corrosion and Stress Corrosion Cracking Implications" by Yinan Jiao, Wenyue Zheng, David Guzonas, and Joseph Kish describes the assessment of long-term microstructure stability.

- "Development of High Performance Pressure Tube Material for Canadian SCWR Concept" by L. Walters and S. Donohue demonstrates the selection of new materials for pressure tube application. 